\title{
Secondary Postpartum Hemorrhage Following Cesarean Section
}

\author{
Bul-Bul S', Susan ZS ${ }^{2}$, Jahan $\mathbf{R}^{3}$, Nayeem A ${ }^{4}$, Rahman $F^{5}$, Zakaria RE ${ }^{6}$, Rahman $\mathbf{S}^{7}$
}

Conflict of Interest: None Financial Support: None Received: 27 March 2017 Accepted: 22 May 2017 www.banglajol.info/index.php/JSSMC

Key words: Pregnancy, childbirth, postpartum, hemorrhage, delivery, reproductive Severe, acute, maternal, morbidity, tertiary care hospital.

\begin{abstract}
Background: Complications of pregnancy and childbirth have always been one of the leading causes of death and disability among women of reproductive age in developing countries .Globally, postpartum haemorrhage is the single most important cause of maternal death, accounting for about $25 \%$ of the total and claiming an estimated 1,50,000 lives annually. Among the postpartum hemorrhage, the primary postpartum hemorrhage is more prevalent, but sufferings from secondary postpartum hemorrhage have been emerging. With the rising trend of cesarean section rate, the incidence of secondary postpartum hemorrhage is also rising.
\end{abstract}

Objective: The objectives of this study is to evaluate secondary postpartum hemorrhage cases following cesarean section and vaginal delivery with the aim of reducing the maternal mortality at child bearing age.

Methods: This is a cross sectional observational study in the department of Obstetrics and Gynaecology, DMCH, by purposive sampling method. Total 100 cases of secondary PPH were observed during 1st January 2013 to 31 December 2013.

Result: In this study, among the cases 67\% were following cesarean section and 33\% were following vaginal delivery, mean age of the patients were 29 year, parity ranges from 1 to 5. Regarding the outcome of secondary PPH, severe anaemia, anaemic heartfailure, renal failure and DIC were common in cesarean sections along with hazards of massive blood transfusion and jaundice. 7 patients were died in post cesarean cases and 2 died in post vaginal delivery cases. Causes of death were due to hemorrhagic shock \& septicemia.

Conclusion: In this is study, the rate of secondary PPH is $67 \%$ following cesarean section which is very much alarming. The outcome of secondary PPH following cesarean section is worse than vaginal delivery.

[J Shaheed Suhrawardy Med Coll 2017; 9(1): 23-25] DOI: http://dx.doi.org/10.3329/jssmc.v9i1.37255

\section{Introduction}

Secondary PPH is defined as excessive vaginal bleeding from 24 hours after delivery upto 6 weeks postpartum. ${ }^{4}$ Unlike primary $\mathrm{PPH}$, there is no clear definition for the

1. Dr. Surayea Bul Bul, Junior Consultant (Obs \& Gynae), Shaheed Suhrawardy Medical College Hospital, Sher-e-Bangla Nagar, Dhaka.

2. Dr. Zobaida Sultana Susan, Junior Consultant, (Obs \& Gynae),Shaheed Suhrawardy Medical Medical College and Hospital, Dhaka

3. Dr. Raunak Jahan, Junior Consultant (Obs \& Gynae), Shaheed Suhrawardy Medical College Hospital, Sher-e-Bangla Nagar, Dhaka.

4. Dr. Abu Nayeem, Assistant Professor, Shaheed Suhrawardy Medical College Hospital, Sher-e-Bangla Nagar, Dhaka.

5. Dr. Farzana Rahman, Junior Consultant (Obs \& Gynae), Shaheed Suhrawardy Medical College Hospital, Sher-e-Bangla Nagar, Dhaka.

6. Dr. Rooh-e-Zakaria, Assistant Professor, (Obs \& Gynae), Shaheed Suhrawardy Medical College Hospital, Sher-e-Bangla Nagar, Dhaka.

7. Dr. Sumana Rahman, Junior Consultant (Obst. \& Gynae), Govt. Employees' Hospital, Dhaka

Correspondence to: Dr. Surayea Bul Bul, Junior Consultant (Obs \& Gynae), Shaheed Suhrawardy Medical College Hospital, Sher-eBangla Nagar, Dhaka. quantity of blood loss and this can vary from increased lochia to massive haemorrhage. The diagnosis is therefore subjective which may account for the variation in reported incidence.

\section{Aims and objectives: \\ General objective: \\ To evaluate the secondary PPH . \\ Specific objectives : \\ To observe the rate of secondary $\mathrm{PPH}$.}

To explore the risk factors association for developing secondary PPH.

To determine the complications of secondary PPH.

To evaluate the management.

To determine the case fatality.

To compare the outcome of secondary PPH following cesarean section and vaginal delivery.

To formulate the recommendation for reduction of complications. 
Methodology : Selection criteria:

Inclusion criteria:

Patients with secondary PPH following cesarean section and vaginal delivery.

Exclusion criteria:

Primary PPH

Data collection tool: by structural data collection form.

Data collection technique: from patient and hospital records.

Statistical analysis: risk factors have been analysed by logistic regression model. Statistical analysis has been made by SPSS for windows version 13.0. 95\% confidence limit has been considered. Probability value 0.05 has been considered as the level of significance.

\section{Results:}

Table 1

\begin{tabular}{l}
\multicolumn{4}{c}{$\begin{array}{c}\text { Incidence of secondary } \\
\text { vaginal delivery } \\
\text { vaging }\end{array}$} \\
\begin{tabular}{lccc} 
Total no of population & 100 & $\%$ & $95 \%$ CI \\
\hline Following CS & 67 & 67 & $58-76 \%$ \\
Following NVD & 33 & 33 & $24-42 \%$ \\
\hline
\end{tabular}
\end{tabular}

Table-II

Comparison of outcome of secondary PPH following CS and vaginal delivery

\begin{tabular}{lcccc} 
Outcome & Following CS & $\%$ & Following VD & $\%$ \\
\hline Severe anaemia & 48 & 71.64 & 28 & 84.85 \\
Anaemic heart failure & 7 & 10.45 & 2 & 6.06 \\
DIC & 2 & 2.98 & 0 & 0 \\
Massive blood transfusion hazard & 1 & 1.49 & 1 & 3.03 \\
Renal failure & 3 & 4.48 & 0 & 0 \\
Jaundice & 1 & 1.49 & 1 & 3.03 \\
Death & 7 & 10.44 & 2 & 6.06 \\
\hline
\end{tabular}

Table-III

\begin{tabular}{|c|c|c|c|}
\hline \multicolumn{4}{|c|}{ Causes of secondary PPH $(n=100)$} \\
\hline Cause & Total no & Following cs & Following vaginal delivery \\
\hline Retained placental bits & 38 & $20(52.63 \%)$ & $18(47.37 \%)$ \\
\hline Sub involution & 20 & $14(70 \%)$ & $6(30 \%)$ \\
\hline Infection & 42 & $33(78.60 \%)$ & $9(21.40 \%)$ \\
\hline
\end{tabular}

Table-IV

Case fatality due to secondary PPH following CS and vaginal delivery

\begin{tabular}{lcccc} 
Cause of death & $\begin{array}{c}\text { No of death } \\
(\mathrm{cs})\end{array}$ & $\begin{array}{c}\text { No of death } \\
(\mathrm{vd})\end{array}$ & $\begin{array}{c}\text { Time interval } \\
\text { between } \\
\text { cs and death }\end{array}$ & $\begin{array}{c}\text { Time interval } \\
\text { between } \\
\text { vd and death }\end{array}$ \\
\hline Haemorrhagic shock & 3 & 1 & 4 days & 3 days \\
Septicemia with haemorrhage & 1 & 1 & 7 days & 4 days \\
Internal haemorrhage & 3 & & 4 days & 7 days \\
\hline
\end{tabular}

Relaparotomy was needed in all this $\operatorname{cases}(\mathrm{n}=9)$ 


\section{Discussion:}

This study was conducted in DMCH to evaluate the secondary PPH cases following cesarean section and vaginal delivery. The study period was 12 months, starting from January 2010 to December 2010.Among them 67\% was delivered by cesarean section and $33 \%$ was by vaginal delivery. In $\mathrm{DMCH}$,facilities for emergency cesarean section is available round the clock and patients came here for treatment and complications .So, the incidence of complicated patients in this hospital is high. In $\mathrm{DMCH}$, in 12 months period, total admitted cases of PPH following vaginal delivery were 616 , among them primary PPH was $74.35 \%$ and secondary $\mathrm{PPH}$ was $25.65 \%$. secondary $\mathrm{PPH}$ following vaginal delivery were $29.75 \%$ but following cesarean section were $70.25 \%$.So it is evident that secondary PPH was more common following cesarean section.

In this study, secondary PPH following cesarean section was $67 \%$ and following vaginal delivery was 33\%.This findings were consistent with a similar study done by Rouf S et al, 2007 at $\mathrm{DMCH}^{5}$ where $45.80 \%$ relaparotomy was done in secondary PPH cases. The age range of patients was from 22 to 38 year with the mean age of 299 year. Parity ranges from 1-5. Among the study population, 95\% were housewives and 5\% were working ladies.80\% belonged to low socio-economic condition, $55 \%$ had no antenatal check up, 70\% had previous 1 cesarean section, $6 \%$ had 2 cesarean sections . Relative risk of developing secondary $\mathrm{PPH}$ was more when repeat cesarean section was done. In this study, $68 \%$ patient had no previous surgery, of them,33\% had vaginal delivery and 35\% had cesarean section delivery. $22 \%$ of cases, primary operation was done at DMCH, 22\% cesarean section was done in Dhaka city, in $23 \%$ cases, operation was done at hospital outside Dhaka city, therefore $45 \%$ patients were referred to $\mathrm{DMCH}$, due to development of secondary PPH following cesarean section .As a tertiary care hospital, this scenario was quite normal.

The outcome of secondary PPH following cesarean section and vaginal delivery of this study were remarkable. Severe anaemia following cesarean section was observed in $71.64 \%$ while in case of vaginal delivery it was $84.85 \%$. Anaemic heart failure in post cesarean cases

was $10.45 \%$ and it was $6.06 \%$ in post vaginal delivery cases. Renal failure and DIC occurred in $2.98 \%$ and $4.48 \%$ cases respectively, of secondary PPH in cesarean section. None of them were reported in cases of vaginal delivery. In post cesarean section cases, 7 patients died and in post vaginal delivery, 2 patients died.

The case fatality due to secondary PPH following cesarean section was more than vaginal delivery. Out of 9 deaths, 7 were secondary PPH following cesarean section. Maximum number of death was $33.33 \%$, was due to hemorrhagic shock and it occurred between 1-4 days following cesarean cases. Other cases were septicemia with hemorrhage and internal hemorrhage with coagulation failure. Maternal mortality was quite high in patients who required relaparotomy. In African study ${ }^{6}$,it was $9.1 \%$ and Indian study ${ }^{7} 6 \%$ patient required admission in ICU and $12 \%$ patient required massive blood transfusion more than 10 units.

\section{Conclusion:}

This study provides a profile of secondary PPH following cesarean section and vaginal delivery and their association in a tertiary teaching hospital of the capital city of Bangladesh . Although the cesarean section delivery can be a life saving operation, serious complications could arise following operation and mandates patient to return to the theatre. In this study, the rate of secondary PPH in 67\% following cesarean section is very much alarming. The risk association for secondary PPH is - post cesarean pregnancy, obstructed labour, placenta previa, gestational hypertension, retained placental bits, sub involution. The outcome is alarming enough to make us think about this burning issue. Even after proper management within a short period of time, there is case fatality which should make us concerned. Definitely the outcome of secondary PPH following cesarean sections is worse than that of vaginal delivery.

\section{Acknowledgements}

The authors gratefully acknowledge the support from Prof. Ferdousi Islam Lipi and Prof. Maliha Rashid, Dhaka Medical College Hospital.

\section{References:}

1. Ramanathan G, Arulkumaran S, Postpartum Hemorrhage, J Obstet Gynaecol Can 2006; 28(11): 967-973 .

2. Abou Zahr C: Antepartum and postpartum haemorrhage . In Murray, CJL, Lopez Ad, eds.Health dimentions of sex and reproduction: The global Burden of sexually transmitted disease, HIV, Maternal conditions, Prenatal disorder and congenital anomalies. Cambridge, MA: Harvard school of public health on behalf of theWHO and theWorld bank; 1998(Global burden of disease and injury series, No. 165-189

3. AbouZahr C : Global Burden of maternal death and disability. In Rodek C, ed. Reducing maternal death and disability in pregnancy, Oxford: Oxford University press; 2003; 1-11

4. Thompson W, Harper MA. : Postpartum haemorrhage and abnormality of third stage of labour. In Chamberlain G, Steer P, eds. Turnbull's Obstetrics $3^{\text {rd }}$ edn. Edinbugh; Churchill Livngstone, 2001;619-33

5. Rouf S, Sharmin S, Dewan F, Akhter S: Relaparotomy after cesarean section: Experience from a tertiary referral and teaching hospital of Bangladesh, Bangladesh J Obstet Gynaecol, 2009, vol s24(9)

6. Seffah J. D. Relaparotomy after cesarean section, International journal of gynaecology obstetrics 2005; 88 : 253-57

7. Seal S1, Kamiliya G,Bhattacharyya SK, Mukherji J. and BhattacharyyaAR,, Relaparotomy after cesarean section delivery; Experience from an Indian teaching hospital, J Obstet gynaecol Res, 2007; 33(6); 804-9. 